Available online on 15.01.2021 at http://jddtonline.info
(c) 2011-21, publisher and licensee JDDT, This is an Open Access article which permits
unrestricted non-commercial use(CC By-NC), provided the original work is properly cited
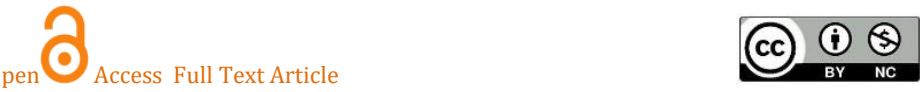

Research Article

\title{
Treatment of high blood pressure in diabetic patients and risk of undernutrition in a population in extreme Western Algeria
}

\author{
Hamza Nadjib Merad-boudia ${ }^{*}$, Majda Dali-Sahi ${ }^{1}$, Youcef Kachekouche ${ }^{1}$, Nouria Dennoun-Medjati ${ }^{1}$, \\ Takwa Salmi ${ }^{1}$, Pr Abderahim Meziane ${ }^{2}$ \\ (1) Department of Biology, Laboratory of Analytical Chemistry and Electrochemistry, University of Tlemcen, 13000, Algeria \\ (2) Department of Cardiology, University Hospital Tlemcen, 13000, Algeria
}

\section{Article Info:}

Article History:

Received 19 Oct 2020;

Review Completed 12 Dec 2020

Accepted 21 Dec 2020;

Available online 15 Jan 2021

Keywords:

Treatment; high blood pressure; risk of undernutrition

Cite this article as:

Merad-boudia HN, Dali-Sahi M, Kachekouche Y, Dennoun-Medjati N, Salmi T, Meziane PA, Treatment of high blood pressure in diabetic patients and risk of undernutrition in a population in extreme Western Algeria, Journal of Drug Delivery and Therapeutics. 2021; 11(1):8-12 DOI:

http://dx.doi.org/10.22270/jddt.v11i1.4467

*Address for Correspondence:

Hamza Nadjib Merad-boudia, Department of Biology, Laboratory of Analytical Chemistry and Electrochemistry, University of Tlemcen, 13000, Algeria

\section{Abstract}

Introduction: Assessing the risk of undernutrition in hypertensive diabetics is essential. It makes it possible to detect undernutrition for better care. The objective of our study is to describe the factors influencing this undernutrition.

Methods: A descriptive study was conducted on a sample of 366 diabetics with hypertension and 326 with normo-glycemic hypertension aged 50 years and over. Patients were enrolled at the University Hospital in Tlemcen from January to June 2018. The data collection was carried out using a questionnaire: The MNA (The Mini Nutritional Assessment).

Results: The study made it possible to establish the profile of subjects at high risk of undernutrition. In our sample, age was not correlated with risk of malnutrition in diabetic hypertensives and normo-glycemic hypertensives respectively $(\mathrm{p}=$ 0.304 and $p=0.444)$. The linear regression model uses gender as an ageindependent factor that affects the risk of undernutrition $(p=0.001)$. BMI was one of the most relevant variables for predicting the occurrence of undernutrition $(\mathrm{p}=$ 0.000 ). Thus, diabetic hypertensive patients in our study who were treated with an Angiotensin II receptor blockers, an angiotensin converting enzyme inhibition or an $\mathrm{ARB} /$ diuretic combination were more at risk of undernutrition $(\mathrm{p}=0.009, \mathrm{p}=$ 0.026 and $\mathrm{p}=0.013$ )

Conclusion: Particular attention should be paid to diabetic hypertensive subject. The treatment of hypertension in diabetics aggravates this malnutrition. Thus, a nutritional status assessment should be established in any diabetic hypertensive patient allowing appropriate therapeutic management to avoid all complications associated with undernutrition.

\section{Introduction}

Therapy and nutritional counselling are an integral part of diabetes treatment and self-management. However, undernutrition is frequently underestimated in hypertensive diabetics because its clinical manifestations are non-specific. Mini Nutritionnal Assessement (MNA) is a tool for screening for undernutrition that can be used at the time of diagnosis of diabetes in hypertensive patients and in treatment followup. The pathogenesis of hypertension in diabetics is complex and involves several biological and environmental factors, as well as a genetic predisposition, therefore, diabetic hypertension presents a greater risk of problems and complications 1. Although hypertension is a common pathology in diabetics (80\% in type 2 diabetes) ${ }^{2}$, there are no studies that assess the prevalence of undernutrition in this category of patients in association with drug combinations. The objective of this study is to assess the risks associated with undernutrition in this category of patients recruited at the University Hospital of Tlemcen.

\section{Methodology}

A descriptive study was carried out on a sample of 692 individuals, 366 diabetics with hypertension, and 326 hypertensives with normal blood sugar aged 50 years and over, recruited at the University Hospital of Tlemcen from January to June 2018. The data collection was done using a questionnaire: The MNA. Sensitive and specific, the latter is internationally validated.

\section{Statistical analyses:}

Data processing was performed using Minitab 16 software. A linear regression study was conducted to determine a predictive model of the risk of undernutrition in hypertensive diabetics. The Student test $(\mathrm{t})$ for the 
comparison of two averages and the Chi-Square test for the comparison of percentages. The statistical significance level was set at $\mathrm{p}<0.05$.

\section{Results}

In our population, we note a sex ratio Male to Female of 0.44 for diabetic hypertensive patients, and 0.78 for non-diabetic hypertensive patients, in favour of a more pronounced female prevalence among diabetic hypertensive patients with a significantly higher percentage of diabetic hypertensive women (69\%) compared to that of nondiabetic hypertensive women (56\%).

The percentage of men with hypertension without diabetes $(44 \%)$ is significantly higher than the percentage of men with hypertension with diabetes $(31 \%)$ with a p-value of (0.000).

No significant differences were observed between the mean age of diabetic hypertensive subjects ( $66 \pm 9.75$ years) and the mean age of non-diabetic hypertensive subjects $(65 \pm 10.2$ years) $(p=1.91)$.

The mean BMI (or Quételet index calculated by weight/ height2) of diabetic hypertensive subjects $(27 \pm 4.69 \mathrm{~kg} / \mathrm{m} 2)$ is significantly higher $(0.004)$ than that of non-diabetic hypertensive subjects $(26 \pm 4.33 \mathrm{~kg} / \mathrm{m} 2)$.

The coefficients of variation are 0.17 and 0.16 for diabetic hypertensive and non-diabetic hypertensive subjects respectively, indicating a homogeneous distribution in both groups.

All hypertensive patients had been on the same antihypertensive therapy for at least one year. The percentages of diabetic hypertensive subjects receiving antihypertensive monotherapy (67\%) and dual antihypertensive therapy (free or combined) (33\%) are similar to the percentages of non-diabetic hypertensive subjects receiving monotherapy (68.09\%) and dual therapy $(31.90 \%)$ with $\mathrm{p}=0.804$.

For subjects taking ACE inhibitors, there is a difference close to the significance threshold $(\mathrm{p}=0.052)$, the percentage of non-diabetic hypertensive subjects treated by ACE inhibitors $(15.95 \%)$ is higher than that of diabetic hypertensive subjects $(10.92 \%)$.

For the other treatment classes (A2RA, BB, diuretic, calcium channel blocker, A2RA/diuretic, IEC/diuretic), there is a nearly balanced distribution between the two groups of patients (diabetic and non-diabetic hypertensive). No significant differences were observed.

The assessment of the risk of undernutrition by the MNA score (in its full version, with a total score between (17-23.5) reveals an insignificant increase in the risk of undernutrition $(p=0.274)$ in non-diabetic hypertensive patients $(42 \%)$ compared to diabetic hypertensive patients (38\%).

Table 1: Characteristics of the study population

\begin{tabular}{|c|c|c|c|}
\hline Parameters & Diabetic hypertensives & Non-Diabetic hypertensives & p-value \\
\hline Gender & $\begin{array}{l}\text { M } 113(30,87 \%) \\
\text { W } 253(69,12 \%)\end{array}$ & $\begin{array}{l}\text { M } 143(43,86 \%) \\
\text { W } 183(56,13 \%)\end{array}$ & 0,000 \\
\hline Age (years) & $65,73 \pm 9,75$ & $64,3 \pm 10,54$ & 0,191 \\
\hline BMI $\left(\mathrm{kg} / \mathrm{m}^{2}\right)$ & $26,85 \pm 4,69$ & $25,85 \pm 4,33$ & 0,004 \\
\hline $\begin{array}{l}\text { Angiotensin } 2 \text { receptor } \\
\text { antagonist }\end{array}$ & $\begin{array}{l}\text { A2RA } 186(23,49 \%) \\
\text { Others } 280(76,50 \%)\end{array}$ & $\begin{array}{l}\text { A2RA } 170(21,47 \%) \\
\text { Others } 256(78,52 \%)\end{array}$ & 0,525 \\
\hline Beta blockers ( BB) & $\begin{array}{l}\text { BB } 59(16,12 \%) \\
\text { Others } 307(83,87 \%)\end{array}$ & $\begin{array}{l}\text { BB } 53(16,25 \%) \\
\text { Others } 273(83,74 \%)\end{array}$ & 0,961 \\
\hline Diuretics & $\begin{array}{l}\text { Diuretics } 13(3,55 \%) \\
\text { Others } 353(69,44 \%)\end{array}$ & $\begin{array}{l}\text { Diuretics } 7(2,14 \%) \\
\text { Others } 319(97,85 \%)\end{array}$ & 0,271 \\
\hline Calcium inhibitors & $\begin{array}{l}\text { Calcium inhibitors } 48(13,11 \%) \\
\text { Others } 318(86,88 \%)\end{array}$ & $\begin{array}{l}\text { Calcium inhibitors } 40(12,26 \%) \\
\text { Others } 286(87,73 \%)\end{array}$ & 0,739 \\
\hline ACE inhibitors (ACEI) & $\begin{array}{l}\text { ACEI } 40(10,92 \%) \\
\text { Others } 326(89,07 \%)\end{array}$ & $\begin{array}{l}\text { ACEI } 52(15,95 \%) \\
\text { Others } 274(84,04 \%)\end{array}$ & 0,052 \\
\hline A2RA/diuretic & $\begin{array}{l}\text { A2RA/ Diuretics } 98(26,77 \%) \\
\text { Others } 268(81,42 \%)\end{array}$ & $\begin{array}{l}\text { A2RA/ Diuretics } 86(26,38 \%) \\
\text { Others } 240(73,61 \%)\end{array}$ & 0,906 \\
\hline ACEI/diuretic & $\begin{array}{l}\text { ACEI/ Diuretics } 22(6,01 \%) \\
\text { Others } 344(93,98 \%)\end{array}$ & $\begin{array}{l}\text { ACEI/ Diuretics } 18(5,52 \%) \\
\text { Others } 308(94,47 \%)\end{array}$ & 0,783 \\
\hline Type of therapy & $\begin{array}{l}\text { Mono } 246(67,21 \%) \\
\text { Bi } 120(32,78 \%)\end{array}$ & $\begin{array}{l}\text { Mono } 222(68,09 \%) \\
\text { Bi } 104(31,90 \%)\end{array}$ & 0,804 \\
\hline Risk of undernutrition & $\begin{array}{l}\text { R } 140(38,25 \%) \\
\text { NR } 226(61,74 \%)\end{array}$ & $\begin{array}{l}\text { R } 138(42,33 \%) \\
\text { NR } 188(57,66 \%)\end{array}$ & 0,274 \\
\hline
\end{tabular}


The impact of age on undernutrition in normoglycemic hypertensives and diabetic hypertensives was assessed by a simple linear regression,

There is no correlation between age and undernutrition in the two groups investigated (Figures 1 and 2).

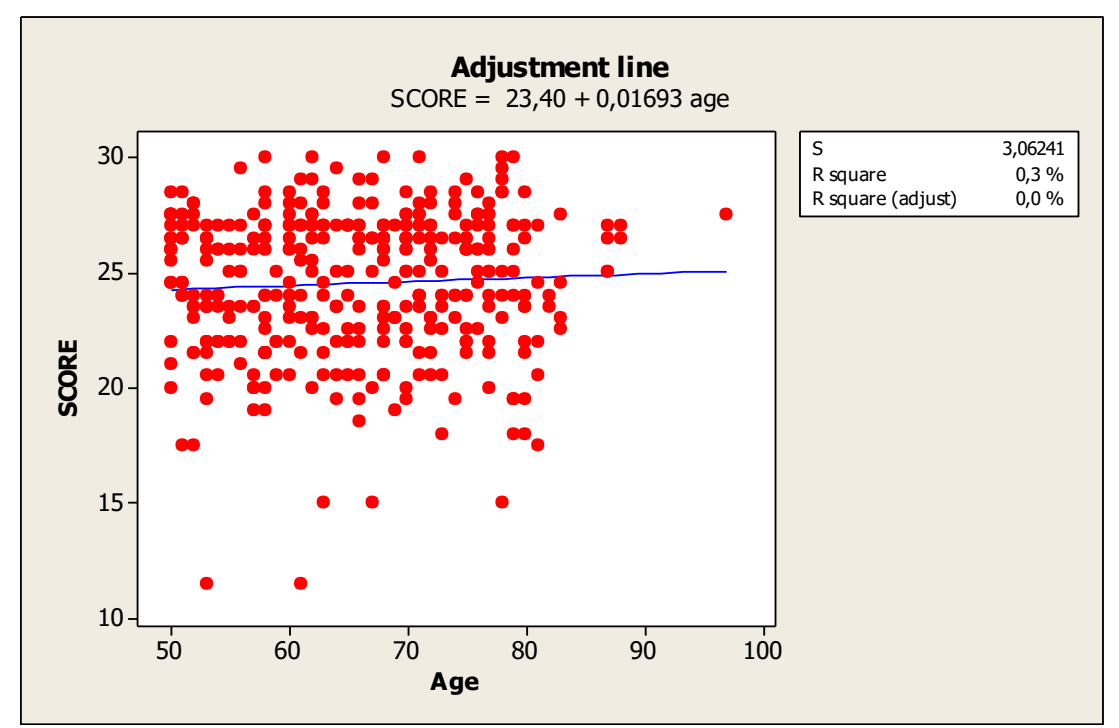

Figure 1: Correlations between undernutrition score and age in hypertensive diabetics

The simple linear regression (Figure 1) and Pearson's correlation show no correlation between undernutrition and age in diabetic hypertensive patients ( $\mathrm{r}=0.054 ; \mathrm{P}=0.304)$.

Similarly, the simple linear regression (Figure 2) and Pearson's correlation show that the score is not age correlated in nondiabetic hypertensive patients with a correlation coefficient of -0.043 and a p-value of 0.444 .

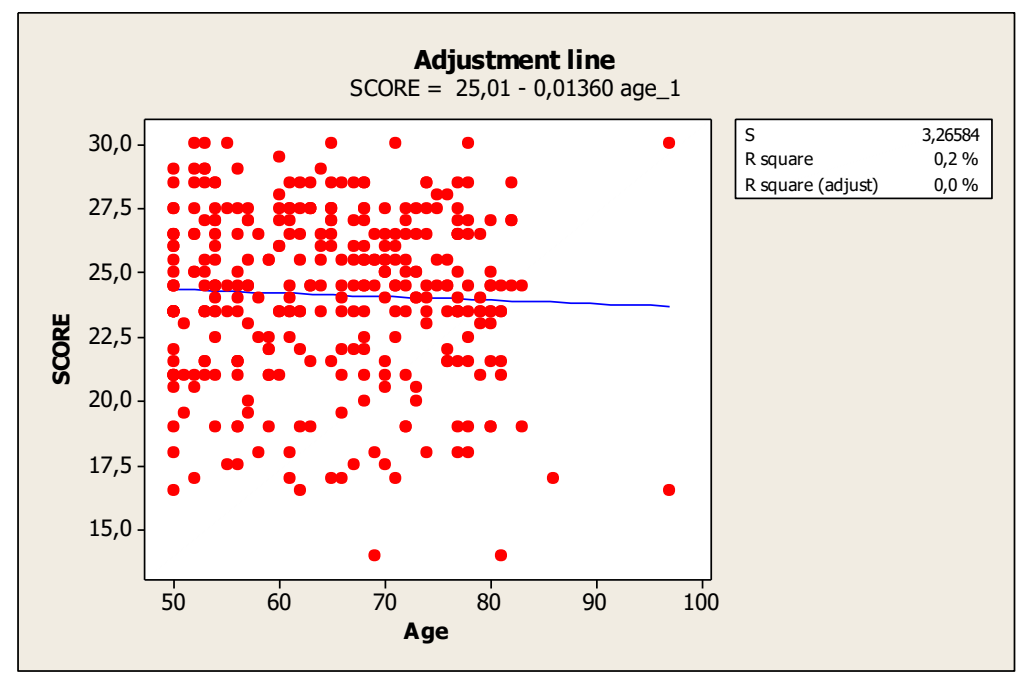

Figure 2: Correlations between score and age in non-diabetic hypertensive patients

There is no difference in most anthropometric and biological parameters between the two groups of hypertensive patients. On the other hand, the regression results (Figures 1 and 2) show that gender, BMI, A2RA, ACEI, and A2RA/D combination have an effect on the score (risk of undernutrition).

Table2: Regression variables

\begin{tabular}{|l|l|l|l|l|}
\hline Predictor & Coeff & Coef ErT & T & P \\
\hline Constant & 18,380 & 1,132 & 16,23 & 0,000 \\
\hline Sex & 0,8294 & 0,2442 & 3,40 & 0,001 \\
\hline BMI & 0,15775 & 0,02579 & 6,12 & 0,000 \\
\hline A2RA & 1,4147 & 0,5422 & 2,61 & 0,009 \\
\hline ACEI & 1,2943 & 0,5795 & 2,23 & 0,026 \\
\hline A2RA/D & 1,3263 & 0,5335 & 2,49 & 0,013 \\
\hline
\end{tabular}

$\mathrm{S}=3.05295 \mathrm{R}$ square $=8.2 \% \mathrm{R}$ square (adjust) $=6.8 \%$. 
Table 3: Analysis of variance

\begin{tabular}{|l|l|l|l|l|l|}
\hline Source & DF & Sum of squares & CM & F & P \\
\hline Regression & 10 & 563,472 & 56,347 & 6,05 & 0,000 \\
\hline Residual error & 681 & 6347,248 & 9,320 & & \\
\hline Total & 691 & 6910,720 & & & \\
\hline
\end{tabular}

\section{Discussion}

A statistical model was developed to assess the risk of malnutrition in hypertensive diabetic subjects in extreme Western Algeria: Characteristics retained significantly related to undernutrition in hypertensive diabetics are: Sex, BMI, and the treatment of hypertension.

It is recommended, without specificity for the elderly, to screen for undernutrition through medical diagnosis and comorbidity ${ }^{4}$. In this study, the patients enrolled were 50 years of age or older. This corresponds to the age used in several studies reported by Ferry et al in 20075.

As our results show, age is not correlated with the risk of malnutrition in diabetic hypertensive patients as well as in non-diabetic hypertensive patients. Elderly people are not necessarily malnourished, several studies have identified situations at risk of undernutrition in elderly people unrelated to age ${ }^{6,7}$. Thus age could be a confounding factor.Our analysis uses sex as a factor, independent of age, that affects the risk of undernutrition $(p=0.001)$. In a Chinese cohort in Hong Kong, among the risk factors associated with weight loss were gender 8 . Our results also show that BMI is one of the most relevant variables for predicting the occurrence of undernutrition $(p=0.000)$. ANAES and NICE recommend for the screening of adult undernutrition and the use of BMI 9, 10 .

Population mortality studies show that there is a "U-shaped" association between BMI and mortality rates between 20 and $27 \mathrm{~kg} / \mathrm{m}^{2}$ depending on age and sex. A decrease in BMI is significantly associated with an increase in mortality. ${ }^{11}$. It is important to note the share of treatment in undernutrition, the purpose of high blood pressure treatment is not only to restore blood pressure figures to normal. But we must also avoid deterioration in nutritional status. In the review by Alibhai et al 13 , these treatments appear to be one of the most frequent causes of involuntary weight loss, in accordance with the recommendations of the ESPEN ${ }^{14}$.

Diabetic hypertensive patients in our study who were treated with an A2RA, ACE inhibitor or A2RA/diuretic combination were at higher risk of undernutrition ( $p=$ $0.009, p=0.026$ and $p=0.013$ ). From a nutritional point of view, these two classes of antihypotensive drugs do not seem to have no side effects and may therefore increase the risk of undernutrition ${ }^{19}$.

In dual antihypertensive therapy, even if the combination of A2RA and diuretics is significantly more effective than each of the individual components 20 , the latter are not without risk and are associated with a risk of undernutrition ( $\mathrm{p}=$ 0.013). Crogan et al found similar results. Among 266 residents over 65 years of age living in a retirement home, one of the factors associated with undernutrition was diuretic use $(p=0.004)$ 21. Although the ESC/ESH recommendations advocate fixed associations in the treatment of hypertension because they "simplify treatment and promote compliance" 22 . The choice of antihypertensive combinations must also take into account the risk of undernutrition. HAS experts warn against long-term drug treatments, particularly the use of diuretics, which puts the elderly at risk of undernutrition 11. The CRITERE study conducted in France concluded that practitioners preferentially combine a calcium channel blocker rather than a diuretic, using renal impairment as the determinant of choice in patients at cardiovascular risk 23 .

\section{Conclusion}

The population of hypertensive diabetic patients is a population at high risk of early undernutrition (from age 50). This work finds a statistically significant relationship between gender, BMI, treatment of hypertension, i.e. A2RA, ACE inhibitors and diuretics. The use of the latter can provide an explanation of the underlying mechanisms of the increased risk of undernutrition observed in hypertensive diabetic subjects in our study population.

\section{Conflict interest: No}

\section{References}

(1) Campbell NRC, Gilbert RE, Leiter LA, and al. hypertension in type 2 diabetics: Update on pharmacological treatment. Canadian Family Physician. 2011; 57(9):e347-e353.

(2) Diyane Kh, Elmghari G, El Ansari N. Characteristics of the association of type 2 diabetes and high blood pressure in the subject aged 65 and over. Pan Afr Med D. 2013; 14:100

(3) Newman AB, Yanez D, Harris T, Duxbury A, Enright PL, Fried LP, and al.Weight change in old age and its association with mortality. J Am Geriatr Soc ; 2001 ; 49(10):1309- 18

(4) American Society for Parenteral and Enteral Nutrition. Guidelines for the use of parenteral and enteral nutrition in adult and pediatric patients. J Parenter Enteral Nutr ; 2002; 26(Suppl 1):1SA-138SA.

(5) Ferry, M., Alix, E. \& Brocker, P. 2007. Nutrition of the elderly person. 3rd edition, Masson, Paris.p 303.

(6) Alibhai SMH, Greenwood C, Payette H. An approach to the management of unintentional weight loss in elderly people. Can Med Assoc J ; 2005 ; 172(6): 773-80.

(7) Ferry M, Alix E, Brocker P, Constans T, Lesourd B, Mischlich D, and al. 2002 Nutrition of the elderly person. Paris: MASSON.

(8) . Woo J, Ho SC, Sham A.Longitudinal changes in body mass index and body composition over 3 years and relationship to health outcomes in Hong Kong Chinese age 70 and older. J Am Geriatr Soc ; $2001 ; 49(6): 737-46$.

(9) National Agency for Health Accreditation and Evaluation. 2003. Diagnostic evaluation of protein-energy malnutrition in hospitalized adults. Saint-Denis La Plaine: ANAES.

(10) National Collaborating Centre for Acute Care.2006. Nutrition support in adults : oral nutrition support, enteral tube feeding and parenteral nutrition. London: Royal College of Surgeons of England.

(11) HAS. 2007. Management strategy in case of protein-energy malnutrition in the elderly[Online]. Available:

http://www.hassante.fr/portail/upload/docs/application/pdf/synt hese_denutrition_personnes_agees.pdf[Accessed 15 April 2012]. 
(12) Beckett, N. S., Peters, R., Fletcher, A. E.,and al. Treatment of hypertension in patients 80 years of age or older. N Engl J Med, 2008; 358:1887-98.

(13) Alibhai, S. M., Greenwood, C. \& Payette, H. An approach to the management of unintentional weight loss in elderly people. CMAJ, 2005; 172:773-80.

(14) ESPEN 2003. ESPEN guidelines for nutrition screening Clin Nutr, 2002; 22:415-21.

(15) Dahlof, B., Devereux, R. B., Kjeldsen, S. E and al. Cardiovascular morbidity and mortality in the Losartan Intervention For Endpoint reduction in hypertension study (LIFE): a randomised trial against atenolol. Lancet, 2002; 359:995-1003.

(16) Lithell, H., Hansson, L., Skoug, I.,and al. The Study on Cognition and Prognosis in the Elderly (SCOPE): principal results of a randomized double-blind intervention trial. J Hypertens, 2003; $21: 875-86$

(17) Papademetriou, V., Farsang, C., Elmefeldt, D., and al . Stroke prevention with the angiotensin II type 1-receptor blocker candesartan in elderly patients with isolated systolic hypertension: the Study on Cognition and Prognosis in the Elderly (SCOPE). J Am Coll Cardiol, 2004; 44:1175-80.
(18) ALLHAT. The, Allhat Officers Coordinators for the, Allhat Collaborative Research Group.Major outcomes in high-risk hypertensive patients randomized to angiotensin-converting enzyme inhibitor or calcium channel blocker vs diuretic: The antihypertensive and lipid-lowering treatment to prevent heart attack trial (allhat). JAMA, 2002; 288:2981-2997.

(19) Loesche, W. J., Bromberg, J., Terpenning, M. S., and al . Xerostomia, xerogenic medications and food avoidances in selected geriatric groups. J Am Geriatr Soc, 1995; 43:401-7.

(20) Melian, E. \& Jarvis, B. 2002. Candesartan Cilexetil plus Hydrochlorothiazide Combination. Drugs, 62, 787-816.

(21) Crogan, N. L., Corbett, C. F. \& Short, R. A. The minimum data set: predicting malnutrition in newly admitted nursing home residents. Clin Nurs Res, 2002; $11: 341-53$.

(22) Mancia, G., Laurant, S., Agabiti-rosei, E., and al Reappraisal of European guidelines on hypertension management: a European Society of Hypertension Task Force document. J Hypertens, 2009; $27: 2121-58$

(23) Vaisse, B., Girerd, X. \& Pouchain, D. CRITERE study, Use of fixed combinations of antihypertensive agents containing an inhibitor of the renin-angiotensin system. Analysis of medical practices in France, 2009; p 8. 